\title{
A Study on the Effect of the Regulations on the Application of Industrial Injury Insurance for Persons Exceeding the Statutory Retirement Age
}

\author{
Huanhuan Li \\ School of law, Southwest University, Chongqing 400715, China \\ 17784410245@163.com
}

Keywords: labor relations; labor relation; retirement age; industrial injury

Abstract: At present, more and more people who exceed the statutory retirement age are still actively involved in work. However, it is very controversial whether the damage suffered by such personnel can be regarded as an industrial injury. Based on the case analysis, this paper aims to determine the relationship between employers who exceed the statutory retirement age and the employing unit, and to study whether the industrial injury insurance regulations can be applied to person exceeding the statutory retirement age.

\section{Introduction}

Wang Chenghua was on September 24, 1958, belonging to the Agricultural Register. From March to June 2013, August to November 5, 2013, Wang Chenghua has been working in the Ningxia Geological Engineering School (hereinafter referred to as "Engineering School") in the management and cleaning of female dormitory buildings, with a monthly salary of RMB 1,500. The general affairs office of the Engineering School was responsible for the attendance of Wang Chenghua and others. Wang Chenghua and Engineering School had not signed a labor contract, the Engineering School also did not pay for the injury insurance fee for Wang Chenghua, that's to say, Wang Chenghua did not participate in industrial injury insurance. At 7:30 on November 5, 2013, when Wang Chenghua cleaned dormitory building, he became ill and was sent to the hospital and died after being rescued (Cardiogenic sudden death).

The third person, Tian Xiaoying (Daughter of Wang Chenghua) filed an application for labor injury certification with the defendant (Yinchuan City Bureau of Human Resources and Social Security) on May 15, 2014. The Yinchuan Human Resources and Social Security Bureau on June 5 and December 5, 2014 respectively made the $<$ Decision of the Authorized Industrial Injury $>$ ([2014] No. 807) and <Determination of Correction for Industrial injury>([2014] No. 807-1).The Engineering School refused to accept the decision on the Industrial injury and appealed to the court to request the decree to cancel the specific administrative actions made by the defendant (Yinchuan City Bureau of Human Resources and Social Security) and to oblige the defendant to make an affirmative decision not to be considered as an industrial injury. It was also found out that the wages of Wang Chenghua during the work of the plaintiff (Engineering School) had all been settled. 


\section{Identification of Labor Relations between Super-retirees and Employers}

\subsection{From the perspective of currently valid laws and regulations}

First of all, the Labor Contract Law stipulates that employers establish labor relations with laborers from the date of their employment. In establishing a labor relationship, a written labor contract shall be concluded. If the employer and the employee conclude a labor contract prior to employment, the labor relationship is established from the date of employment. This shows that the basic legal relationship that causes labor relations is employment, not the conclusion of labor contracts. The conclusion of a labor contract is an obligation to establish employers and laborers in labor relations, and is also an important proof of labor relations. Labor law and labor contract law only stipulate the establishment of labor relations, and there is no clear stipulation on the dissolution of labor relations, and only the termination of the labor contract ${ }^{[1]}$. Article 18 of the $<$ Industrial Injury Insurance Regulations > also stipulates that even if a written labor contract is not signed, as long as there is employment, the laborer provides labor for payment and accepts the employers' management, the laborer and the employer have a de facto labor relationship, and an application for industrial injuries can be filed. Labor contracts are a manifestation of the existence of labor relations, the termination of a labor contract does not necessarily mean the termination of labor relations ${ }^{[2]}$. Although the two parties did not sign a labor contract in the case, Wang Chenghua worked in Engineering School from March to June and August to November 5, 2013, the labor relationship between the two has been established since the date of employment.

Second, the premise of industrial injury recognition is that there is a labor relationship between the laborer and the employer. Although Wang Chenghua has exceeded the statutory retirement age, during March-June, August-November 5, 2013, she engaged in female dormitory building management and cleaning work and receive monthly labor compensation of 1,500 yuan. From Article 15 of the <Labor Law> of our country, we can see that our country's law only prohibits employers from recruiting minors under the age of 16 , that is, it only makes prohibitive provisions on the lower limit of the age of the laborers. It is not forbidden whether laborers who exceed the statutory retirement age can establish labor relations with employers, nor do they stipulate that workers who exceed the statutory retirement age cannot enjoy the various benefits of laborers ${ }^{[3]}$. Therefore, the labor relations formed between laborers who exceed retirement age and employers are in compliance with the law.

Finally, the $<$ Labor Contract Law $>$ does not clearly stipulate that workers who reach the statutory retirement age must terminate the labor relationship with the employer. Instead, workers began to enjoy basic pension insurance benefits in accordance with the law as one of the conditions for terminating labor contracts and labor relations.

At the same time, Article 7 of the Interpretation of the Supreme People's Court on $<$ Several Issues Concerning the Application of Law in the Trial of Labor Disputes (III)>indicates that division of labor relations and labor relation is based on the criterion of "enjoying endowment insurance or receiving pensions”. That is to say, persons who exceed the statutory retirement age can still establish labor relations with employers.

\subsection{From the perspective of the attributes of labor relations}

Labor relations is a kind of legal relationship in social law, and there are obvious differences in the legal relations between equal subjects based on the freedom of contract, such as labor relations and employment relations. Based on the status of social public managers, the state conducts specific investigations on the strengths of the parties to labor relations and their respective social status and status, and follows labor rights standard and the employer's obligation-based thinking, it's purpose 
is to achieve concrete equality of labor relations, equality of results and substantial equality, so that the pattern of interests of both parties meets the requirements of social public interests. It is precisely for this reason that there are not only property relations(economic relations) but also personal relations(administrative affiliation) between labor relations parties. In addition to providing labor, laborers also have to accept the management of employers, obey their arrangements, abide by their rules and regulations, and become members of employers. This is the most obvious place in which labor relations are distinguished from other civil law relations between other equal subjects, and it is also the most important feature and symbol of labor relations ${ }^{[4]}$. However, for those who do not enjoy endowment insurance and who exceed the statutory retirement age, there is no essential difference between the basic status and those who do not exceed the statutory retirement age. The affiliation relationship and personal attachment relationship between normal laborers and employers still exist in laborers who exceed the statutory retirement age, and even this relationship may be more obvious and profound ${ }^{[5]}$.

\subsection{From the public interest perspective}

Since 1980, with the continuous improvement of China's social and economic level, the rapid development of health care and education, people's life expectancy has become longer, which has led to an increasingly prominent population aging phenomenon in China. In 2000, China began to enter an aging society. The risk of a serious shortage of social security funds has gradually increased and the national social security level is extremely low. With the acceleration of industrialization and urbanization, the right to contracted management of rural land has continued to circulate, and a large number of rural laborers have begun to leave the countryside to seek employment opportunities in large cities in order to seek life ${ }^{[6]}$. If the issue of the protection of the rights and interests of this group of people cannot be solved as soon as possible, it will certainly have a serious impact on the process of industrialization and urbanization in our country, and it will even seriously threaten social stability and harmony. From the nature of this group of people, they are at the bottom of society and belong to an absolute disadvantaged group; if the country allows them to enter into the protection scope of voluntary and equal contracts, it is undoubtedly to put them in a more embarrassing position and make disadvantaged people even more vulnerable.

\section{Industrial Injury Insurance Regulations Applied to Workers of Super-retirement Ages}

The labor relations between the laborers who exceed the legal retirement age and the employing units are determined to be in harmony with and coordinated with the relevant opinions of the current Supreme People's Court and the specific practices of industrial injury determination. The administrative court of the Supreme People's Court shall acknowledgment of the industrial injury to the peasants who have worked in cities that exceed the statutory retirement age due to industrial injuries or deaths (Including traffic accidents that occur on the way to and from work) ${ }^{[7]}$. It is the current direct basis for the protection of labor rights and interests after injury accident of laborers beyond the legal retirement age. The functional departments in some places are negative or even inconsistent with regard to industrial injuries that exceed the statutory retirement age, the main reason is that they have reservations about the nature of the legal relationship. This behavior is obviously only a mechanical dogmatic style of doing things in accordance with the law, seriously neglecting the meaning and nature of the law itself ${ }^{[8]}$.

Whether a person who exceeds the statutory retirement age is qualified as a laborer, whether they can constitute a labor relationship with employing unit, and whether they can be included in the subject scope of the industrial injury assessment when an employment injury occurs. The judgment should be based on the spirit of the superior law and on the specific circumstances of the case, they 
should not be directly excluded from the scope of the subject of industrial injury identification. But no matter what, in order to maintain social stability and harmony and promote stable and healthy economic development in China, identifying the relationship between a person who exceeds the legal retirement age and employers as a labor relationship is relatively a better choice, and there is no essential difference between a person who exceeds the legal retirement age and the average worker when injury accidents occur at work. He must identify the work injury according to the Regulations on Employment Injury Insurance ${ }^{[9]}$. However, in order to maintain social stability and harmony and promote stable and healthy economic development in China, combining the actual conditions of China's socialist market economy and China's current national conditions, it will exceed the relationship between statutory retirement ages and employers. It is relatively good to determine that the labor relationship is a relatively good choice, and if any person who exceeds the statutory retirement age has an injury accident at work, there is no essential difference with the general worker. If the employer can't pay the cost of the work injury insurance, which will result in the employer's liability for the work injury insurance, then this situation should also be one of the types of employment risks of the employer. Because employers generally use this type of personnel to know that the type of personnel exceeds the statutory retirement age, and the employer clearly knows that there is such a risk. Therefore, the person who exceeds the statutory retirement age is applicable to industrial injury insurance regulations

\section{Summary}

Those who exceed the statutory retirement age participate in the work will benefit the society and the economy, they are in a relatively weak position and need more protection from the state, society, and employers. Identifying the relationship between laborers who exceed the legal retirement age and employers as a labor relationship, they apply industrial injury insurance regulations in case of accidents at work, it is conducive to economic development and social harmony and stability.

\section{References}

[1] Meng, Diyun, and Y. Yin. "Legal Thought on Perfecting the Industrial Injury Insurance System of Migrant Workers." Public Administration \& Law 19.02(2010):343-364.

[2] Glofcheski, Ra. "Health and safety at work III - statutory compensation for work-related injury, death and disease." Employment Law \& Practice in Hong Kong (2010).

[3] Williamson, John B, and T. K. Mcnamara. "Why Some Workers Remain in the Labor Force Beyond the Typical Age of Retirement." Ssrn Electronic Journal (2001).

[4] Coles, Peter. "Industrial injury." Nature 339.6221(1989):163-163.

[5] Colleran, Marie. "Beware impact on personal injury and employment claims with proposed scrapping of retirement age." Strategic Direction 26.11(2010):26-29.

[6] Micheel, Frank, J. Roloff, and I. Wickenheiser. "The Impact of Socioeconomic Characteristics on Older Employees' Willingness to Continue Working in Retirement Age." Comparative Population Studies 35.4(2010):833-868.

[7] Yang, Hong. "Discussion on the industrial injury insurance problem of peasant workers in our country." Journal of Dalian University (2004).

[8] Okabe, Noriko. "Creating of customer loyalty by cabin crew A study of the relation between emotional labor and job performance." Transportation Research Procedia 25(2017):149-164.

[9] Edqvist, M, et al. "Midwives' Management during the Second Stage of Labor in Relation to Second-Degree Tears-An Experimental Study." Birth 44.1(2017):86-94. 